\title{
Mycoplasma conjunctivae in domestic small ruminants from high mountain habitats in Northern Spain
}

Xavier Fernández-Aguilar ${ }^{1,2}$, Óscar Cabezón ${ }^{1,2}$, Ignasi Marco1, Gregorio Mentaberre1, Joachim Frey³, Santiago Lavín ${ }^{1}$ and Jorge R López-Olvera ${ }^{1 *}$

\begin{abstract}
Background: Infectious keratoconjunctivitis (IKC) is a clinical condition affecting eyes of domestic and wild Caprinae worldwide, and Mycoplasma conjunctivae is considered the primary causative agent of IKC in sheep, goats and wild Caprinae. Domestic ruminants from high mountain habitats share grazing areas with wild mountain ungulates, such as chamois (Rupicapra spp.), Alpine ibex (Capra ibex) and European mouflon (Ovis aries musimon), and domestic sheep seem to act as M. conjunctivae reservoir. In this study, the presence of $M$. conjunctivae in domestic sheep and goats from the two main mountain ranges of Northern Spain, the Pyrenees and the Cantabrian Mountains, has been investigated.

Results: Eye swabs were obtained from 439 domestic small ruminants selected from flocks that seasonally graze in alpine meadows during three consecutive years (2011-2012-2013). Seventy-nine out of the 378 domestic sheep (20.9\%) tested positive to a M. conjunctivae specific real time-PCR (rt-PCR) in at least one eye, whereas all the 61 sampled domestic goats were negative. Statistically significant higher prevalence and higher proportion of infected flocks ( $P<0.001)$ was observed in the Pyrenees $(25.7 \%$; 12 flocks out of 13$)$, where $M$. conjunctivae is widespread and probably endemic in domestic sheep, than in the Cantabrian Mountains (7.8\%; one flock out of six). Twenty-five sheep (three from the Pyrenees and 22 from the Cantabrian Mountains) which showed clinical signs consistent with infectious keratoconjunctivitis (IKC) were negative by rt-PCR. In contrast, 62 out of the 71 (87.3\%) M. conjunctivae-positive sheep from the Pyrenees and the eight positive sheep from the Cantabrian Mountains were asymptomatic.
\end{abstract}

Conclusions: This study provides rt-PCR-based evidences of M. conjunctivae maintenance in domestic sheep, as well as a relationship between prevalence in domestic sheep and previously reported $M$. conjunctivae and IKC in wild ruminants. Domestic goats do not seem to play an important role in the epidemiology of M. conjunctivae in alpine habitats from Northern Spain.

Keywords: Goat, Sheep, Infectious keratoconjunctivitis, Mycoplasma conjunctivae, Spain, Pyrenees, Cantabrian mountains

\footnotetext{
* Correspondence: jordi.lopez.olvera@uab.cat

'Servei d'Ecopatologia de Fauna Salvatge (SEFaS), Departament de Medicina

i Cirurgia Animals, Facultat de Veterinària, Universitat Autònoma de

Barcelona, 08193 Bellaterra, Spain

Full list of author information is available at the end of the article
}

\section{Biomed Central}

(C) 2013 Fernández-Aguilar et al.; licensee BioMed Central Ltd. This is an open access article distributed under the terms of the Creative Commons Attribution License (http://creativecommons.org/licenses/by/2.0), which permits unrestricted use, distribution, and reproduction in any medium, provided the original work is properly cited. 


\section{Background}

Infectious keratoconjunctivitis (IKC) is a clinical condition affecting eyes of domestic and wild Caprinae worldwide. Several infectious agents such as Mycoplasma conjunctivae, Chlamydophila psittaci or Moraxella ovis (formerly Branhamella ovis) have been isolated from eyes of small ruminants affected by IKC [1]. However, $M$. conjunctivae is considered the primary causative agent of IKC in sheep, goats and wild Caprinae [1-4]. Susceptibility to $M$. conjunctivae infection differs among host species. While in sheep and goats IKC usually appears in form of transitory blindness causing little concern and economic consequences, pathogenicity to wild species is generally high though variable, causing outbreaks with morbidity and mortality up to $30 \%$ [1].

The epidemiology of $M$. conjunctivae is particularly worth investigating in mountain habitats, where domestic ruminants share grazing areas with susceptible wild mountain ungulates during late spring (May-June) to early fall (September-October), such as chamois (Rupicapra spp.), Alpine ibex (Capra ibex) and European mouflon (Ovis aries musimon) [1,5]. Interspecific transmission may occur [6], and domestic sheep seem to play a key role as a reservoir host for M. conjunctivae in such a complex scenario of host interaction $[7,8]$. Several outbreaks of IKC have been described in domestic sheep and goats worldwide [3,9-11], but few active surveillance studies have been conducted in small domestic ruminants, particularly in high mountain habitats.

In this study, the presence of $M$. conjunctivae in domestic sheep and goats from the two main mountain ranges of Northern Spain, the Pyrenees and the Cantabrian Mountains, has been investigated (Figure 1). M. conjunctivae and IKC outbreaks have been reported in Pyrenean chamois (Rupicapra pyrenaica pyrenaica) in the Pyrenees $[5,12,13]$, but not in Cantabrian chamois (Rupicapra pyrenaica parva) from the Cantabrian mountains. Therefore, both study areas represent two different epidemiological scenarios.

\section{Methods}

Conjunctival swabs were obtained from below the nictitating membrane from both eyes in 439 physically restrained small ruminants (19 flocks; 378 sheep, 61 goats) from the Catalan Pyrenees (Eastern and Central Pyrenees; 13 flocks; 276 sheep and 24 goats) and the southern side of the Cantabrian Mountains (6 flocks; 102 sheep and 37 goats). Flocks that graze in alpine meadows were selected according its potential contact with wild hosts susceptible to $M$. conjunctivae infection, namely Pyrenean chamois and European mouflon, in the National Game Reserves (NGR) of Freser-Setcases, Cadí, Cerdanya, and Alt Pallars in the Pyrenees, and Cantabrian chamois in the National Park of Picos de Europa and NGR of Mampodre and Riaño in the Cantabrian Mountains. Handling procedures were designed to reduce stress and health risks for subjects, according to European (86/609) and Spanish laws (R.D. 223/1988, R.D.1021/2005), and current guidelines for ethical use of animals in research [14]. A mean number of 20 sheep and goats were randomly sampled within each flock from November to May in three consecutive housing periods (2010-2011, 2011-2012 and 2012-2013) (Table 1). Two flocks in each region were sampled in at least two periods. All the goats were sampled in mixed goat and sheep flocks, except for 20 goats from a goat flock in the Cantabrian Mountains. Clinical signs compatible with IKC were recorded at sampling and swabs were stored at $-20^{\circ} \mathrm{C}$ until analyzed.

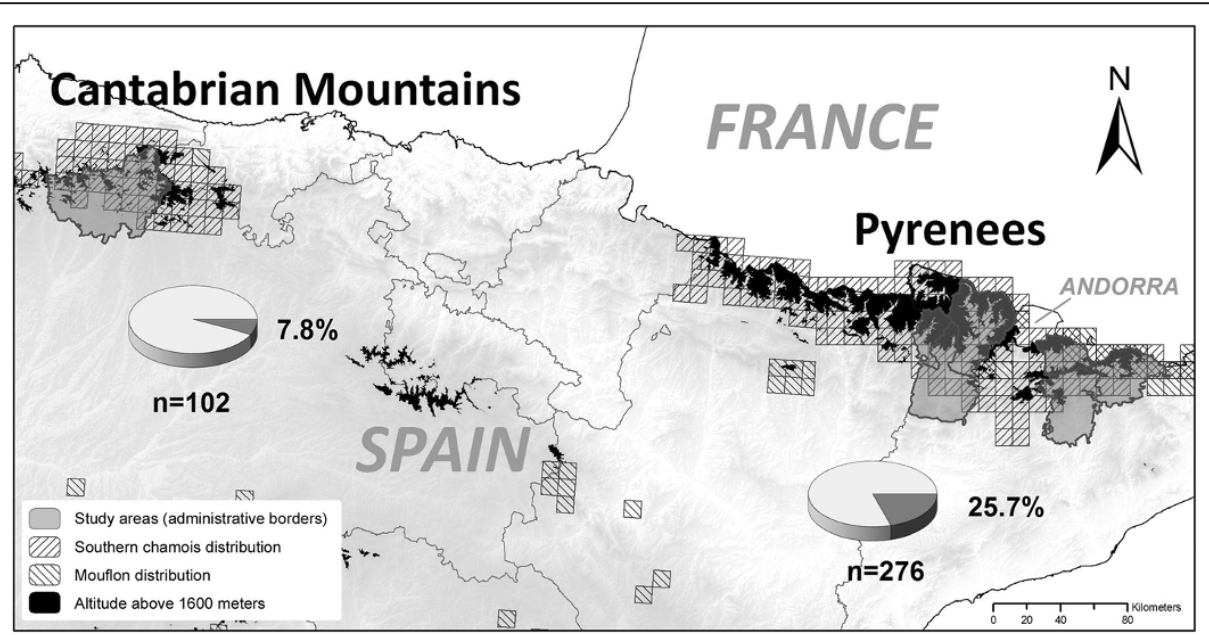

Figure 1 Pie charts showing the prevalence of $M$. conjunctivae in domestic sheep in the Cantabrian Mountains and the Pyrenees. Altitude above 1600 meters is shown in black. Borders for the regions where the sampled flocks graze in alpine meadows are shown in darker grey. Southern chamois and mouflon distribution squares correspond to a 10x10 Km grid. 
During the study period, no outbreak of IKC was detected neither in domestic ruminants or wild mountain ungulates in the study area, though IKC cases in Pyrenean chamois are observed every year (Fernández-Aguilar et al., in prep.).

At the laboratory, swabs were thawed and mixed with $0.5 \mathrm{ml}$ of lysis buffer $(100 \mathrm{mM}$ Tris- $\mathrm{HCl}, \mathrm{pH} 8.5,0.05 \%$ Tween $20,0.24 \mathrm{mg} / \mathrm{ml}$ proteinase $\mathrm{K}$ ) in microcentrifuge tubes and cells were lysed for 60 minutes at $60^{\circ} \mathrm{C}$ and 15 minutes at $97^{\circ} \mathrm{C}$. The presence of $M$. conjunctivae was determined by a TaqMan real-time PCR (rt-PCR) with an exogenous external positive control in each reaction, as previously described [15]. For analysis of $\mathrm{Myco-}$ plasma agalactiae as a potential cause of IKC, the real time PCR method based on the cytadhesin P40 [16] was used as described [17].

Chi-square tests were performed in order to detect statistically significant differences in $M$. conjunctivae prevalence both at flock and individual level according to area and clinical status, using the PROC FREQ of the SAS ${ }^{\circ}$ 9.1.3 System for Windows (SAS Institute, Cary, NC, USA).

\section{Results}

Mycoplasma conjunctivae was detected in at least one eye of 79 out of the 378 domestic sheep (20.9\%) analyzed. Both individual and flock prevalence were significantly higher $(\mathrm{p}<0.001)$ in the Pyrenees $(25.7 \% ; 71$ of 276 sheep; 12 positive flocks out of 13) than in the Cantabrian Mountains (7.8\%; 8 of 102 sheep; one positive flock out of six) (Table 1 and Figure 1). Mean prevalence within infected sheep flocks was $29.9 \%$ (range $6.7 \%$ to $65 \%$ ) in the Pyrenees and $32 \%$ in the only positive flock from the Cantabrian Mountains. The flocks sampled in two periods did not change their status regarding the presence of $M$. conjunctivae (one positive and one negative flock in each region). Moreover, the five sheep sampled twice in the M. conjunctivae-positive flock from the Pyrenees kept their status (two positive and three negative sheep) in both sampling periods which were separated by 12 months.

Clinical signs consistent with IKC, such as ocular discharge, epyphora, mild conjunctivitis and/or corneal opacity were registered in $4.3 \%(12 / 276)$ of the examined domestic sheep from the Pyrenees and in 21.6\% (22/102) in the Cantabrian Mountains (Figure 2). Most of the cases of IKC in sheep from the Pyrenees were associated with the presence of $M$. conjunctivae (75\%), whereas none of the 22 sheep and three goats that showed clinical signs in Cantabrian Mountains had M. conjunctivae in their eyes. As Mycoplasma agalactiae has been reported to be a mycoplasmal cause of IKC in domestic ruminants [18], samples of these sheep were also analyzed by real time PCR for the presence of this pathogen. This analysis did not detect $M$. agalactiae in the eye swabs of these animals. In contrast, 62 out of the $71(87.3 \%)$ M. conjunctivae-positive sheep from the Pyrenees and the eight positive sheep from the Cantabrian Mountains were asymptomatic. In most flocks, IKC was unnoticed by the owners, as clinical cases were found to be occasional and mild. The clinical signs of the two sheep from the Pyrenees which were positive to $M$. conjunctivae in two samplings periods evolved from lachrymation and bilateral conjunctivitis in the first sampling to apparently healthy eyes in the second sampling in one sheep, and conversely for the other sheep.

$M$. conjunctivae was not detected in any of the goats sampled in both study areas (Table 1), although three goats from one flock in the Cantabrian Mountains showed mild clinical ocular signs.

\section{Discussion}

The high prevalence of $M$. conjunctivae in domestic sheep from the Pyrenees and its maintenance over

Table 1 Results of Mycoplasma conjunctivae prevalence assessed by rt-PCR (as described in [15])

\begin{tabular}{|c|c|c|c|c|c|c|c|c|c|}
\hline \multirow[t]{2}{*}{ Sampling period } & \multicolumn{2}{|c|}{$2010-2011$} & \multicolumn{2}{|c|}{ 2011-2012 } & \multicolumn{2}{|c|}{$2012-2013$} & \multicolumn{3}{|c|}{ Total } \\
\hline & Prevalence & Flocks & Prevalence & Flocks & Prevalence & Flocks & Prevalence & $\mathrm{Cl} 95 \%$ & Flocks* \\
\hline \multicolumn{10}{|l|}{ Goats } \\
\hline Pyrenees & NS & NS & $0.0(0 / 10)$ & $0 / 5$ & $0.0(0 / 14)$ & $0 / 3$ & $0.0(0 / 24)$ & - & $0 / 7$ \\
\hline Cantabrian Mountains & $0.0(0 / 5)$ & $0 / 1$ & $0.0(0 / 4)$ & $0 / 1$ & $0.0(0 / 28)$ & $0 / 2$ & $0.0(0 / 37)$ & - & $0 / 2$ \\
\hline Total & $0.0(0 / 5)$ & $0 / 1$ & $0.0(0 / 14)$ & $0 / 6$ & $0.0(0 / 42)$ & $0 / 5$ & $0.0(0 / 61)$ & - & $0 / 9$ \\
\hline \multicolumn{10}{|l|}{ Sheep } \\
\hline Pyrenees & NS & NS & $26.1(29 / 111)$ & $6 / 7$ & $25.4(42 / 165)$ & $7 / 8$ & $25.7(71 / 276)$ & $20.5-30.9$ & $12 / 13$ \\
\hline Cantabrian Mountains & $25.0(3 / 12)$ & $1 / 2^{\dagger}$ & $0.0(0 / 18)$ & $0 / 2$ & $6.9(5 / 72)$ & $1 / 4^{\dagger}$ & $7.8(8 / 102)$ & $2.6-13.0$ & $1 / 5$ \\
\hline Total & $25.0(3 / 12)$ & $1 / 2$ & $22.5(29 / 129)$ & $6 / 9$ & $19.8(47 / 237)$ & $8 / 12$ & $20.9(79 / 378)$ & $16.8-25.0$ & $13 / 18$ \\
\hline Total & $17.6(3 / 17)$ & $1 / 2$ & $20.3(29 / 143)$ & $6 / 10$ & $16.8(47 / 279)$ & $8 / 13$ & $18.0(79 / 439)$ & $14.4-21.6$ & $13 / 19$ \\
\hline
\end{tabular}

NS: Not sampled

*Total number of flocks may no coincide with the sum of all the periods because some of the flocks were re-sampled in more than one period.

${ }^{\dagger}$ In the Cantabrian Mountains there was a single M. conjunctivae-positive flock, sampled in both periods (2010-2011 and 2012-2013). 


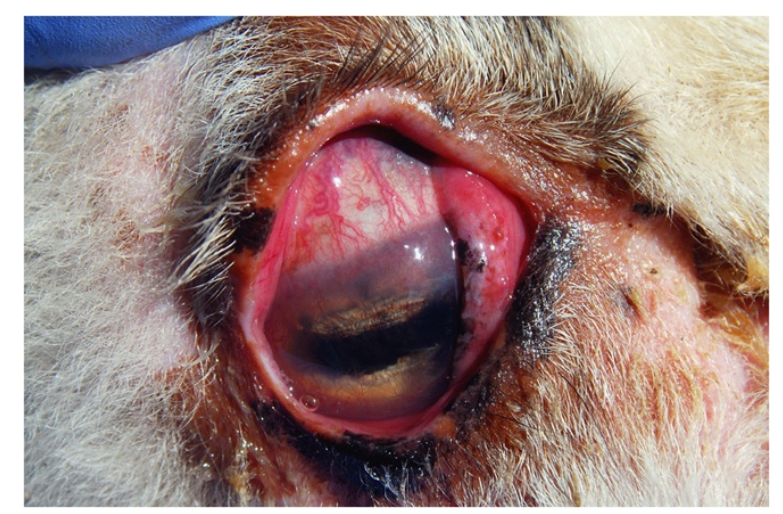

Figure 2 One of the more severe IKC cases observed during the study period, eye of a domestic sheep from the Pyrenees showing epiphora, conjunctival hyperemia, peripheral corneal edema, and neovascularization.

sampling periods (Table 1) indicate that M. conjunctivae infection is widespread among domestic sheep in the Pyrenees, endemic and self-maintained within domestic sheep flocks. This agrees with previous data on $M$. conjunctivae prevalence $(25.8 \%)$ in domestic small ruminants from Central Pyrenees [12] and the wide distribution of $M$. conjunctivae infection in domestic sheep throughout Europe [4,7]. In contrast, the lower prevalence found in the Cantabrian Mountains and the fact that $M$. conjunctivae was detected in only one flock in this region suggest that $M$. conjunctivae is currently less common in this area. Moreover, the only M. conjunctivaepositive flock in the Cantabrian Mountains seasonally migrates to Caceres (South-Western Spain) in winter. Hence, the origin of $M$. conjunctivae in this flock is unclear and could lead to an overestimation of the endemic situation of $M$. conjunctivae in this region. Furthermore, the occurrence of $M$. conjunctivae relative to IKC cases in the two study areas strongly differed. Whereas there is a good agreement between IKC cases and the presence of $M$. conjunctivae in the Pyrenees, this is not the case in the Cantabrian Mountains.

The prevalence of $M$. conjunctivae among asymptomatic sheep was higher than previous data obtained by traditional culture methods [19]. However, strain pathogenicity or individual host factors such as immunity may influence the outcome of clinical disease. Spontaneous clinical recoveries and relapses are a common feature of IKC in sheep [4], which agrees with the clinical evolution of the two positive sheep from the Pyrenees sampled twice, further suggesting the role of sheep as a maintenance host of $M$. conjunctivae in this area, as previously suggested in Switzerland assessed by serology [7] and Central Pyrenees [12].

Several IKC outbreaks caused by $M$. conjunctivae have been reported in domestic goats $[3,9,10]$, and IKC has been experimentally reproduced in goats by inoculating $M$. conjunctivae previously isolated from a goat with IKC [2]. However, the absence of $M$. conjunctivae occurrence in goats in this study, even in mixed flocks with high prevalence of $M$. conjunctivae in sheep, suggests a lower susceptibility to $M$. conjunctivae infection or a host specificity of the strains circulating in the area among domestic sheep. Therefore, domestic goats do not seem to contribute to $M$. conjunctive epidemiology in nonepidemic IKC in mountain habitats from Northern Spain. The finding of sheep and goats negative for $M$. conjunctivae and $M$. agalactiae but showing clinical signs consistent with IKC suggests a possible implication of other pathogens, such as Chlamydophila psittaci, Moraxella ovis, or Listeria monocytogenes previously detected in domestic small ruminants with IKC $[1,19]$. The higher occurrence of $M$. conjunctivaenegative sheep and goats with clinical signs of keratoconjunctivitis in the Cantabrian Mountains suggests that other pathogens may be more relevant than $M$. conjunctivae for keratoconjunctivitis in this region. Although $M$. conjunctivae is considered the main etiological agent of IKC outbreaks in both domestic small ruminants and wild mountain ruminants $[1,2,11]$, pathogens or conditions associated with nonepidemic IKC warrant further research, as previously suggested in wild mountain ungulates [20].

The widespread and consistent presence of $M$. conjunctivae in domestic sheep from the Pyrenees and the less relevant role of this pathogen in the Cantabrian Mountains seem to correspond to previous reports of IKC in wild sympatric susceptible hosts, such as European mouflon and Pyrenean chamois in the Pyrenees [1,5,12,13], but not in Cantabrian chamois from the Cantabrian Mountains. Phylogenetical analyses of $M$. conjunctivae strains circulating in domestic sheep and wild mountain ruminants would help clarifying the specific role of different host species in the epidemiology of IKC from the studied areas, particularly in the Pyrenees.

\section{Conclusions}

This study provides rt-PCR-based evidence of $M$. conjunctivae maintenance in domestic sheep, as well as a relationship between prevalence in domestic sheep and previously reported $M$. conjunctivae and IKC in wild ruminants. This finding adds new relevant information into the epidemiology of $M$. conjunctivae in the domestic-wildlife interface. Domestic goats do not seem to play an important role in the epidemiology of $M$. conjunctivae in alpine habitats from Northern Spain.

Competing interests

The authors declare no competing interests. 


\section{Authors' contributions}

XF and OC collected samples and performed the rt-PCR assays. XF drafted the manuscript. OC conceived the study and critically revised the manuscript. IM, GM and SL provided access to and collected samples, gave technical and material support, and critically revised the manuscript. JF provided the controls for and coordinated the rt-PCR assays, participated in the study design and critically revised the manuscript. JRLO acquired funding, elaborated the study design, collected samples, coordinated the analyses and participated in the elaboration of the draft. All authors read and approved the final manuscript.

\section{Acknowledgements}

The authors are grateful to the owners of the sheep flocks sampled in the Cantabrian Mountains and the Pyrenees for allowing and collaborating in sampling. We would like to give special thanks to veterinary practitioners, Manel Beneria, Joan Jordana, Javier Larrán, Antoni Margalida, Josep Maria Moner, and Joan Plana, as well as veterinary students, for collaborating and participating in field work. The Departament d'Agricultura, Ramaderia, Pesca, Alimentació i Medi Natural of the Generalitat de Catalunya kindly provided access to sample collection in the Pyrenees, as Juan Carlos Peral (Junta de Castilla y León) and the game rangers of the Regional Game Reserves of Mampodre and Riaño did in the Cantabrian Mountains. Many thanks are also expressed to Dr. E. M. Vilei, from the Institute of Veterinary Bacteriology of the University of Bern, who kindly provided positive controls. This study was funded by the research projects CGL2009-11631 and CGL2012-40043-C02-02 of the Spanish MICINN.

\section{Author details}

'Servei d'Ecopatologia de Fauna Salvatge (SEFaS), Departament de Medicina i Cirurgia Animals, Facultat de Veterinària, Universitat Autònoma de Barcelona, 08193 Bellaterra, Spain. ${ }^{2}$ Centre de Recerca en Sanitat Animal (CReSA), UAB-IRTA, Campus de la Universitat Autònoma de Barcelona, 08193 Bellaterra Barcelona, Spain. ${ }^{3}$ Institute of Veterinary Bacteriology, University of Bern, Länggass-Strasse 122, CH-3012 Bern, Switzerland.

Received: 15 May 2013 Accepted: 3 December 2013

Published: 13 December 2013

\section{References}

1. Giacometti M, Janovsky M, Belloy L, Frey J: Infectious keratoconjunctivitis of ibex, chamois and other Caprinae. Rev Sci Tech OIE 2002, 21:335-345.

2. Trotter SL, Franklin RM, Baas EJ, Barile MF: Epidemic caprine keratoconjunctivitis: experimentally induced disease with a pure culture of mycoplasma conjunctivae. Infect Immun 1977, 18:816-822.

3. Ter Laak EA, Schreuder BEC, Smith-Buys CMC: The occurrence of Mycoplasma conjunctivae in the Netherlands and its association with infectious keratoconjunctivitis in sheep and goats. Vet Q 1988, 10:73-83.

4. Hosie BD: Infectious Keratoconjunctivitis. In Diseases of Sheep. Edited by Aitken ID. Oxford: Blackwell Publishing; 2007:342-345.

5. Marco I, Mentaberre G, Ballesteros C, Bischof DF, Lavín S, Vilei EM: First report of Mycoplasma conjunctivae from wild Caprinae with infectious keratoconjunctivitis in the Pyrenees (NE Spain). J Wildl Dis 2009, 45:238-241.

6. Belloy L, Janovsky M, Vilei EM, Pilo P, Giacometti M, Frey J: Molecular epidemiology of Mycoplasma conjunctivae in Caprinae: transmission across species in natural outbreaks. Appl Environ Microbiol 2004, 69:1913-1919

7. Janovsky M, Frey J, Nicolet J, Belloy L, Goldschmidt-Clermont E, Giacometti M: Mycoplasma conjunctivae infection is self-maintained in the Swiss domestic sheep population. Vet Microbiol 2001, 83:11-22.

8. Giacometti M, Janovsky M, Jenny H, Nicolet J, Belloy L, GoldschmidtClermont E, Fery J: Mycoplasma conjunctivae infection is not maintained in Alpine chamois in eastern Switzerland. J Wild Dis 2002, 38:297-304.

9. Barile MF, Del Giudice RA, Tully JG: Isolation and characterization of Mycoplasma conjunctivae sp. n. from sheep and goats. Infect Immun 1972, 5:70-76.

10. Baas EJ, Trotter SL, Franklin RM, Barile MF: Endemic caprine keratoconjunctivitis: recovery of Mycoplasma conjunctivae and its possible role in pathogenesis. Infect Immun 1977, 18:806-815.

11. Naglic T, Hajsig D, Frey J, Seol B, Busch K, Lojkic M: Epidemiological and microbiological study of an outbreak of infectious keratoconjunctivitis in sheep. Vet Rec 2000, 147:72-75.
12. Arnal M, Herrero J, de la Fe $C$, Revilla M, Prada C, Martínez-Durán D, Gómez-Martín A, Fernández-Arberas O, Amores J, Contreras A, GarcíaSerrano A: Dynamics of an infectious keratoconjunctivitis outbreak by Mycoplasma conjunctivae on pyrenean chamois rupicapra p. Pyrenaica. PLOS ONE 2013, 8(De Luco DF):e61887. doi:10.1371/journal.pone.0061887.

13. Panella P, Herrero J, Canut J, García-Serrano A: Long-Term monitoring of Pyrenean chamois in a protected area reveals a fluctuating population. Hystrix 2010, 21:183-188.

14. Association for the study of animal behaviour (ASAB): Guidelines for the treatment of animals in behavioural research and teaching. Anim Behav 2006, 71:245-253.

15. Vilei EM, Bonvin-Klotz L, Zimmermann L, Ryser-Degiorgis MP, Giacometti M Frey J: Validation and diagnostic efficacy of a TaqMan real-time PCR for the detection of Mycoplasma conjuntivae in the eyes of infected Caprinae. J Microbiol Meth 2007, 70:384-386.

16. Fleury B, Bergonier D, Berthelot X, Peterhans E, Frey J, Vilei EM: Characterization of P40, a cytadhesin of Mycoplasma agalactiae. Infect Immun 2002, 70:5612-5621.

17. Oravcová K, López-Enríquez L, Rodríguez-Lázaro D, Hernández M: Mycoplasma agalactiae p40 gene, a novel marker for diagnosis of contagious agalactiae in sheep by real-time PCR: assessment of analytical performance and in-house validation using naturally contaminated milk samples. J Clin Microbiol 2009, 47:445-450.

18. Rodríguez JL, Poveda JB, Rodríguez F, Ramírez AS, Fernández A, Espinosa de los Monteros A: Ovine infectious keratoconjunctivitis caused by Mycoplasma agalactiae. Small Ruminant Res 1996, 22:93-96.

19. Akerstedt J, Hofshagen M: Bacteriological investigation of infectious keratoconjunctivitis in Norwegian sheep. Acta Vet Scand 2004, 45:19-26.

20. Mavrot F, Vilei EM, Marreros N, Signer C, Frey J, Ryser-Degiorgis MP: Occurrence, quantification, and genotyping of Mycoplasma conjunctivae in wild Caprinae with and without infectious keratoconjunctivitis. J Wildl Dis 2012, 48:619-631.

doi:10.1186/1746-6148-9-253

Cite this article as: Fernández-Aguilar et al:: Mycoplasma conjunctivae in domestic small ruminants from high mountain habitats in Northern Spain. BMC Veterinary Research 2013 9:253.

\section{Submit your next manuscript to BioMed Central and take full advantage of:}

- Convenient online submission

- Thorough peer review

- No space constraints or color figure charges

- Immediate publication on acceptance

- Inclusion in PubMed, CAS, Scopus and Google Scholar

- Research which is freely available for redistribution

Submit your manuscript at www.biomedcentral.com/submit
C Biomed Central 